\title{
Bidirectional Modulation of Hippocampal Long-Term Potentiation under Stress and No-Stress Conditions in Basolateral Amygdala-Lesioned and Intact Rats
}

\author{
Volker Korz and Julietta U. Frey \\ Department of Neurophysiology, Leibniz-Institute for Neurobiology, D-39118 Magdeburg, Germany
}

\begin{abstract}
Hippocampal long-term potentiation (LTP) is widely considered as a cellular model for learning and memory formation. We have shown previously that protein synthesis-independent, early dentate gyrus (DG) LTP, lasting $\sim 4-5 \mathrm{~h}$, can be transformed into a late-LTP with a duration of $\geq 24 \mathrm{~h}$ by a brief acute swim stress experience (high-stress condition). This reinforcement requires the activation of mineralocorticoid receptors and protein synthesis. The basolateral amygdala (BLA) is known to modulate glucocorticoid effects on the consolidation of spatial/contextual memory via a $\beta$-adrenergic mechanism. Interestingly, hippocampal DG-LTP can also be indirectly modulated by $\beta$-adrenergic and cholinergic/muscarinergic processes. Here, we show that the reinforcement of early-DG-LTP under high-stress conditions depends on the processing of novel spatial/contextual information. Furthermore, this reinforcement was blocked in BLA-lesioned animals compared with sham-operated and intact controls; however, it was not dependent on $\beta$-adrenergic or cholinergic/muscarinergic receptor activation. In contrast, under low-stress conditions, the induction of late-LTP in BLA-lesioned animals is facilitated, and this facilitation, again, was dependent on $\beta$-adrenergic activation. The data suggest that DG-LTP maintenance can be influenced by the BLA through different mechanisms: a short-lasting corticosterone-dependent and $\beta$-adrenergic-independent mechanism and a long-lasting mechanism that facilitated hippocampal $\beta$-adrenergic mechanisms.
\end{abstract}

Key words: basolateral amygdala; early-LTP; late-LTP; locus ceruleus; memory; stress

\section{Introduction}

The basolateral amygdala (BLA) plays a pivotal role in the consolidation of memories related to fear and emotions (Kim and Diamond, 2002; McGaugh, 2002, 2004; Seidenbecher et al., 2003). Long-term potentiation (LTP) is a widely considered model for cellular mechanisms of learning and memory consolidation. At least two different phases of LTP can be discriminated: a protein synthesis-independent early-LTP that lasts $\sim 4-5 \mathrm{~h}$ and a protein synthesis-dependent late-LTP maintained longer than $5 \mathrm{~h}$ (Krug et al., 1984) that requires heterosynaptic activation during its induction (Krug et al., 1984; Frey et al., 1988, 1990, 1991, 1993; Otani et al., 1989; Otani and Ben-Ari, 1993). Hippocampal early-LTP can be transformed (reinforced) into a lateLTP by a time-related activation of a heterosynaptic strong input that is mainly involved in the activation of the synthesis of required plasticity-related proteins (PRPs) (Sajikumar and Frey, 2004). Such a heterosynaptic consolidation can be initiated either by direct electrical stimulation of different brain areas structur-

Received March 8, 2005; revised June 28, 2005; accepted June 28, 2005.

This study was supported by the Land Saxony-Anhalt (LSA3475A/1102M). We thank Dr. D. Fields (National Institute of Child Health and Human Development, National Institutes of Health, Bethesda, MD) for critically reading this manuscript, Dr. V. Stefanski (Department of Animal Physiology, University of Bayreuth, Bayreuth, Germany) for analyzing the blood samples, and $\mathrm{G}$. Behnisch and J. Maiwald for excellent technical assistance.

Correspondence should be addressed to Dr. Volker Korz, Leibniz-Institute for Neurobiology, Brenneckestrasse 6, D-39118 Magdeburg, Germany. E-mail: korz@ifn-magdeburg.de.

DOI:10.1523/JNEUROSCI.0910-05.2005

Copyright $\odot 2005$ Society for Neuroscience $\quad$ 0270-6474/05/257393-08\$15.00/0 ally related to the hippocampus (Ikegaya et al., 1996; Frey et al., 2001, 2003; Akirav and Richter-Levin, 2002; Bergado et al., 2003; Vouimba and Richter-Levin, 2005) or by behavioral stimulation (Seidenbecher et al., 1997; Akirav and Richter-Levin, 1999; Straube et al., 2003; Korz and Frey, 2003, 2004; Uzakov et al., 2005).

Under low or moderate stress conditions, both types of reinforcement of DG-LTP have been shown to depend on noradrenergic and cholinergic activation (Ikegaya et al., 1997; Jas et al., 2000; Frey et al., 2001; Straube et al., 2003) and can be modulated by the basolateral amygdala (Abe et al., 1994; Izquierdo, 1994; Ikegaya et al., 1996, 1997; Almaguer-Melian et al., 2003, Nakao et al., 2004). After acute swim stress, we found that DG-LTP reinforcement was dependent on the activation of mineralocorticoid receptors (MRs) by binding of corticosterone (Korz and Frey, 2003). The BLA has been described to modulate glucocorticoid effects on the retrieval and consolidation of spatial/contextual memory by $\beta$-adrenergic mechanisms (Roozendaal, 2003; Roozendaal et al., 2003, 2004).

The aim of the present study was to elucidate the possible role of the basolateral amygdala in reinforcement of early-LTP by behavioral stress. Second, we investigated whether this LTP reinforcement is dependent on the processing of novel spatial/contextual information. To address these questions, we compared the influence of different neuromodulatory systems on LTP modulation under low- and high-stress conditions in BLAlesioned and intact rats. 


\section{Materials and Methods}

Surgery and electrophysiological recording. Male Wistar rats (8 weeks of age) were anesthetized with Nembutal ( $40 \mathrm{mg} / \mathrm{kg}$, i.p.). For electrolytic lesions, a monopolar electrode was lowered stereotaxically into the BLA of both hemispheres [anteroposterior (AP), -2.4; lateral (L), 5.0; 7.6 ventral from dura], and a current of $1.5 \mathrm{~mA}$ over $7 \mathrm{~s}$ was delivered (compare Fig. 2). In sham-operated animals, the electrode was lowered into the BLA without application of electrical current. At the end of the experiments, the correct locations of the lesions were verified histologically. For electrophysiological recording, a monopolar electrode (insulated stainless steel; diameter, $125 \mu \mathrm{m})$ was implanted into the hilus of the dentate gyrus (DG) (AP, $-2.8 ; \mathrm{L}, 1.8 ; 3.2-3.5$ ventral from dura), and a bipolar stimulation electrode was implanted into the medial perforant path (MPP) (AP, -6.9; L, 4.1; 2.2-2.5 ventral from dura). In pharmacologically treated rats, a cannula of $4.5 \mathrm{~mm}$ in length (coordinates: AP, $-0.8 ; \mathrm{L}, 1.6)$ was implanted into the lateral ventricle of the right hemisphere. During electrode implantation, the population-spike amplitude (PSA) was optimized by delivering test pulses. The animals were allowed $\geq 1$ week to recover from surgery.

During recording sessions, electrodes were connected to a swivel by a flexible cable while rats were allowed to move freely in a recording box $(40 \times 40 \times 40 \mathrm{~cm})$. The animals had ad libitum access to food and water. An input/output (I/O) curve was performed 16-17 h before baseline recording by application of test pulses with an intensity of $0.1-0.8 \mathrm{~mA}$ in steps of $0.1 \mathrm{~mA}$. Biphasic constant current pulses ( $0.1 \mathrm{~ms}$ per half-wave) were applied to the perforant path to evoke DG field potentials of $\sim 40 \%$ of the maximum PSA. The responses were amplified and stored on a personal computer.

A stable baseline was registered for $1 \mathrm{~h}$, early-LTP was induced by three tetanic bursts and late-LTP by 10 tetanic bursts at the same stimulus intensity as that used for the test pulses. Each burst consisted of 15 pulses at $200 \mathrm{~Hz}$. Each stimulus was $0.1 \mathrm{~ms}$ in duration, and bursts were delivered at $10 \mathrm{~s}$ interburst intervals. Initially, after $2 \mathrm{~min}$, and then every 15 min after tetanization, five test stimuli (10 s interpulse interval) were applied, and the mean values of field potentials were stored for $8 \mathrm{~h}$ (compare Fig. 1). For analysis and presentation, $1 \mathrm{~h}$ values were averaged over every four $15 \mathrm{~min}$ values for $8 \mathrm{~h}$ and then $24 \mathrm{~h}$ after tetanus. The $2 \mathrm{~min}$ value controlled for the achievement of a sufficient initial potentiation before experimental manipulations, so that changes in potentiation could be related to these manipulations rather than to induction of LTP. Tetanization and experimental manipulations took place between 9:00 and 10:00 A.M. to control for the diurnal rhythm of corticosterone titers.

Five minutes after registration of the third baseline value, hippocampal EEG was recorded over $40 \mathrm{~s}$. A second recording session was performed 20 min after injection of either saline or timolol.

Swim stress procedure. Fifteen minutes after application of a weak tetanus, the animals were transferred from the recording box into a water tank for a 2 min swim (compare Fig. 1). The tank, usually used as a water maze, was a white circular plastic tank (diameter, $1.82 \mathrm{~m}$; height, $58 \mathrm{~cm}$ ) located in an adjacent room. The water level was at $38 \mathrm{~cm}$, and the water temperature was $25 \pm 2^{\circ} \mathrm{C}$. After swimming, the rats were dried with a towel and then transferred back into the recording chamber where LTP was recorded. Pretraining consisted of two 2 min swims (with a 15 min interval between swims) in the same environment as that during the experiments ( $16-17 \mathrm{~h}$ before tetanus).

Behavioral parameters. The behavioral parameters during swimming (swim speed, thigmotaxis, and path lengths) were measured from those animals from which the blood samples were collected. The swim paths were recorded using a videocamera and fed to a video tracking (HVS image analyzer, VP200; HVS Image, Buckingham, UK) and analysis (Watermaze, version 2.17a; Richard Morris and Roger Spooner, University of Edinburgh, Centre of Neuroscience Research, Edinburgh, UK) system located in an adjacent room.

Pharmacology. In pharmacologically treated rats, a cannula of $4.5 \mathrm{~mm}$ in length (coordinates: AP, $-0.8 ; \mathrm{L}, 1.6$ ) was implanted into the lateral ventricle of the ipsilateral hemisphere. In a previous study (Korz and Frey, 2003), we used propranolol, an antagonist of $\beta$-adrenergic receptors, to test for the $\beta$-adrenergic dependence of emotional reinforce-
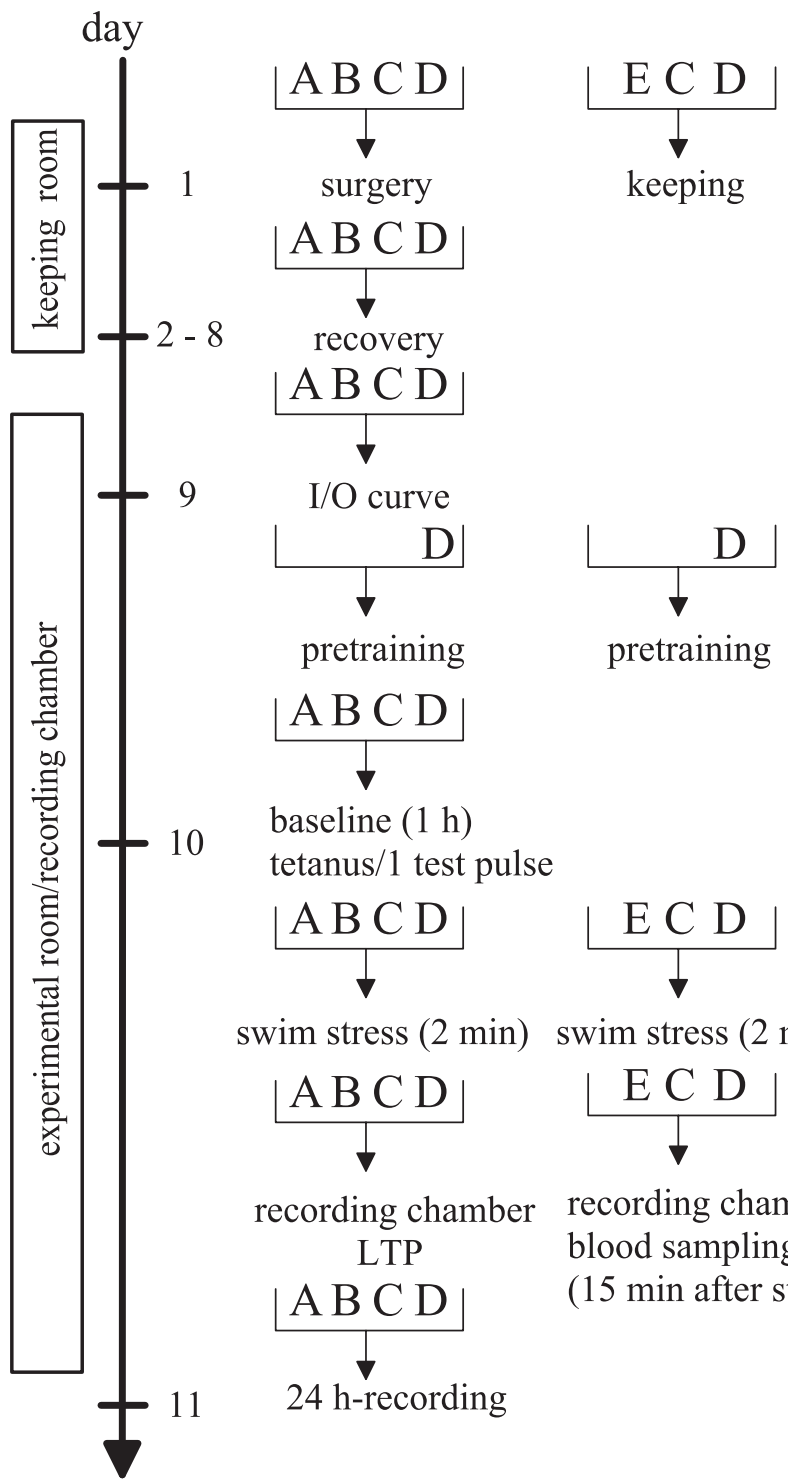

swim stress (2 min)
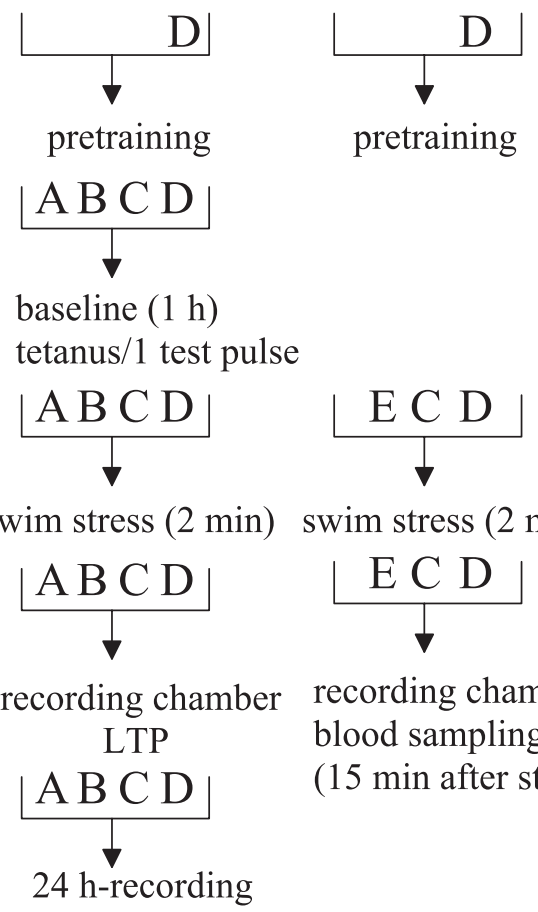

Figure 1. Schema of the experimental design for LTP experiments (left) and blood sampling (right). A, Intact animals; B, sham-operated animals; C, BLA-lesioned animals; D, pretrained animals; $E$, naive animals.

ment. This drug also has a high affinity for serotonergic receptor subtypes (Kasamo et al., 1994; Hentall et al., 2000; Zhelyazkova-Savova and Zhelyazkov, 2003). To increase the specificity of $\beta$-adrenergic receptor blockade in the present study, we used timolol (Sigma, St. Louis, MO) as a reference antagonist. Atropine (Sigma), a cholinergic/muscarinergic receptor antagonist $(0.677 \mu \mathrm{g} / 5 \mu \mathrm{l})$, and timolol $(25 \mu \mathrm{g} / 5 \mu \mathrm{l})$ were dissolved in $0.9 \% \mathrm{NaCl}$. The substances were applied by a Hamilton syringe ( $1 \mu \mathrm{l} / \mathrm{min}$ ) immediately after tetanus. Control animals received the same volume of $\mathrm{NaCl}$.

Hormone analysis. Blood samples from intact animals were taken from animals that were not prepared with electrodes but were otherwise treated identically to the prepared animals during the experiments. For blood sampling from lesioned and sham-operated rats, prepared animals were taken that had no swim experience. Fifteen minutes after a 2 min swim, animals from the different groups were decapitated, and trunk blood was collected (compare Fig. 1). Control animals remained in the recording box and were decapitated at the same time point as experimental animals. Blood was sampled in an Eppendorf (Sigma, Steinheim, Germany) tube and allowed to coagulate on ice for $30 \mathrm{~min}$ and then the 
blood was centrifuged, and the serum was stored at a temperature of $-20^{\circ} \mathrm{C}$. Samples were analyzed by a radioimmunoassay.

Statistics. The general linear model for repeated measures was used for group comparisons in $24 \mathrm{~h}$ of LTP (least significant difference post hoc tests for pairwise comparisons). Comparisons of $8 \mathrm{~h}$ time points in LTP and comparisons of corticosterone levels as well as of power in the spectral analyses were done by one-way ANOVA ( post hoc Dunnett's $t$ tests for pairwise comparisons). Spectral analyses were performed with Chart 5 (version 5.0.2, power lab; ADInstruments, Castle Hill, Australia). Differences in behavior were evaluated with the Kruskal-Wallis H-test and subsequent Mann-Whitney $U$ tests. All tests were two-tailed, and the level of significance was set at $p \leq 0.05$. In all figures, the means and SEM are given.

\section{Results}

Brief acute stress 15 min after application of a weak tetanus resulted in a reinforcement of early- into late-LTP in shamoperated control rats $(p<0.01$; compared with nonstressed sham controls) but not in lesioned rats (Fig. $2 A$ ). The overall comparison revealed a significant difference between groups $\left(F_{(4,30)}=8.07 ; p<0.01\right)$ and a prolonged LTP of sham-operated rats compared with lesioned swimmers $(p<0.01)$. In contrast, under no-stress conditions, application of a weak tetanus resulted in a prolonged LTP $(p=0.01)$ in lesioned animals compared with controls (Fig. $2 B$ ). Application of a strong tetanus induced no additional potentiation in lesioned animals $(p>$ 0.1 ). The induction of late-LTP by a weak tetanus in lesioned animals under no-stress conditions was not a result of increased excitability of dentate gyrus granule cells (i.e., no differences in the I/O characteristics between sham-operated and lesioned animals were detected). We found similar increases in the PSA as a function of the stimulation intensity in both groups (Fig. $3 A$ ) and no difference in the EPSP-PSA relationship (Fig. 3B). Additional evidence for similar spontaneous activity of granule cells in lesioned and sham-operated animals is provided by comparison of the EEGs under no-stress conditions (Fig. 3C). Spectral analyses revealed no differences in the frequency band or the power of hippocampal EEG between sham and lesioned groups or after receiving saline or timolol $\left(F_{(3,36)}=0.57 ; p=0.64\right)$. All animals showed a marked peak in power at $24 \mathrm{~Hz}$, which is within the $\beta$-frequency band.

In previous studies, it has been shown that reinforcement of DG-LTP by electrical stimulation of the BLA was dependent on muscarinergic and $\beta$-adrenergic heterosynaptic activity (Frey et al., 2001). Therefore, we tested whether emotional reinforcement of DG-LTP by behavioral activation of the amygdala was required for these kinds of heterosynaptic activity by intracerebroventricular application of specific receptor antagonists. As shown in Figure 4, this was not the case. We found no difference between groups of intact stressed animals treated with atropine, a cholinergic receptor blocker (Fig. $4 A$ ), or treated with timolol, a $\beta$-adrenoceptor antagonist (Fig. $4 B$ ) and their respective salinetreated control groups $\left(F_{(3,25)}=1.25 ; p=0.31\right.$. $)$

To differentiate between specific effects of timolol under stress and no-stress conditions, we compared experimental groups of intact and BLA-lesioned animals that received different tetanization protocols [specific effects of atropine on DG-LTP have been shown previously (Frey et al., 2001)]. A significant overall difference in PSA at the $8 \mathrm{~h}$ time point $\left(F_{(5,43)}=5.67 ; p=0.001\right)$ could be noted. Post hoc tests against the group that received a strong tetanus in the presence of saline as a control group indicated significantly decreased PSA in intact animals that received a strong tetanus $(p=0.027)$ in the presence of timolol under no-stress conditions (Fig. 4C). Thus, the amount of timolol used

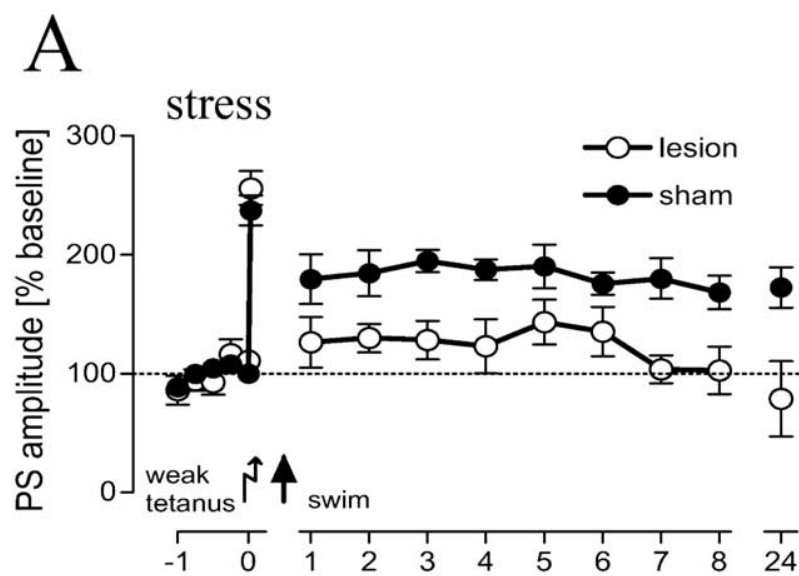

$\mathrm{B}$

time $[\mathrm{h}]$

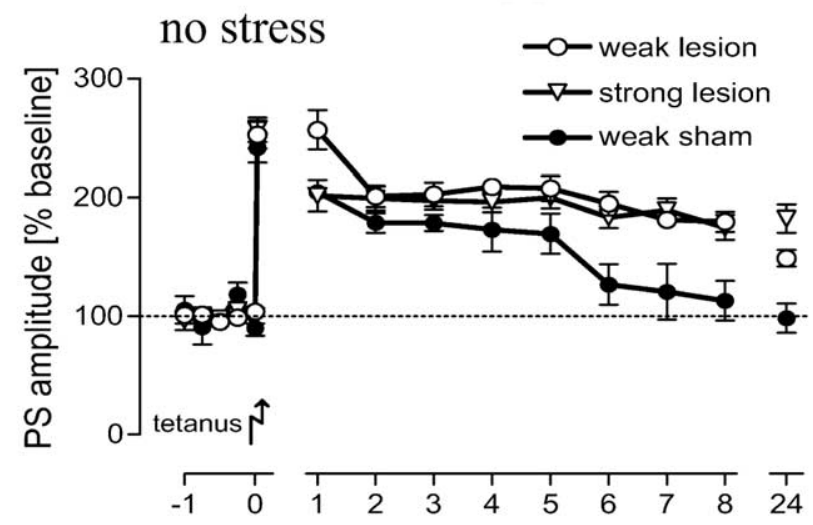

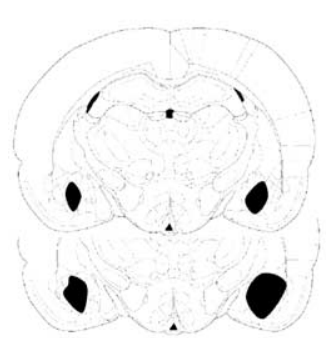

Bregma -3.10

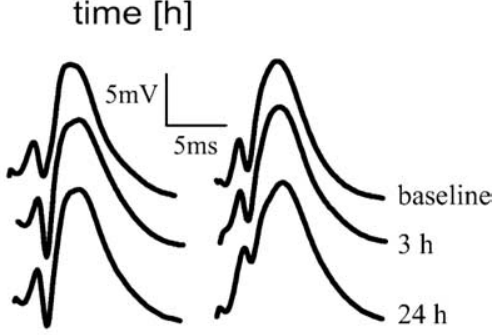

sham lesion
Figure 2. BLA-lesioned $(n=6)$ animals showed a depotentiation and impairment of LTP under stress conditions compared with sham-operated animals $(n=9 ; \boldsymbol{A})$, whereas under no stress conditions, LTP was facilitated (weak lesion; $n=8$ ) after a weak tetanus compared with controls (weak sham; $n=6 ; \boldsymbol{B}$ ). No potentiation beyond that elicited by a weak tetanus could be induced by a strong tetanus (strong lesion; $n=6$ ) in lesioned animals $(\boldsymbol{B})$. The mean and SEM of population-spike amplitudes as percentages from baseline values are shown. Bottom, Representative analog traces at the time points indicated for sham-operated and lesioned animals as well as a scheme of the largest and smallest extent of BLA lesions are shown.

under stress conditions is sufficient to prevent the maintenance of an electrically induced late-LTP compared with control animals under no-stress conditions, whereas early-LTP and baseline values were not affected (Fig. $4 D$ ). The same amount of timolol can also prevent the facilitation of LTP in BLA-lesioned rats $(p=$ $0.001)$ that received a weak tetanus under no-stress conditions (Fig. $4 E$ ). We focused on investigating the $\beta$-adrenergic system, because this is the main and direct modulatory input to the dentate gyrus under no-stress conditions (Ikegaya et al., 1997; Seidenbecher et al., 1997; Frey et al., 2001; Straube et al., 2003). To 
address the question of whether ablating the amygdala interferes with LTP reinforcement because of its involvement in processing novel emotionally charged information, we pretrained animals twice on the day before testing. As shown in Figure $5 A$, we found no difference in LTP between control and pretrained animals $(p>0.1)$. In contrast, pretrained swimmers differed in some behavioral parameters compared with naive swimmers (Fig. $5 B)$, with increased swim path lengths $(U=0 ; p<0.01)$, higher swim speed $(U=0.5 ; p<0.01)$, and decreased thigmotaxis $(U=13 ; p=0.046)$.

In a previous study, the activation of mineralocorticoid receptors by the ligand corticosterone was implicated in the reinforcement of DG-LTP by swim stress (Korz and Frey, 2003). To test whether the hypothalamo-pituitary-adrenal axis may be differentially activated in BLA-lesioned or pretrained rats in comparison with intact naive animals, we collected blood samples from the different groups 15 min after a 2 min swim and measured the serum corticosterone levels. As indicated in Figure 6, we found an overall difference between values because of the stress or no-stress conditions $\left(F_{(5,39)}=47.22 ; p<0.0001\right)$ but no group differences in baseline titers $\left(F_{(2,18)}=0.24\right.$; $p=0.79)$ or stress levels $\left(F_{(2,20)}=0.82 ; p=\right.$

$0.46)$, respectively. The lack of reinforcement in pretrained animals is not a result of decreased corticosterone levels as indicated by similar titers in pretrained compared with naive animals $(p>0.1)$ and a significant increase in corticosterone in both groups compared with controls $\left(F_{(2,19)}=71.17 ; p<0.001\right)$.

\section{Discussion}

In intact and sham-operated animals, we found that DG-LTP reinforcement by acute swim stress did not require $\beta$-adrenergic or muscarinergic/cholinergic heterosynaptic activation; however, under no-stress conditions, $\beta$-adrenergic activation was required for the induction of late-LTP by strong electrical stimulation. In contrast, in animals with lesions of the basolateral amygdala, DG-LTP was completely prevented by swim stress; however, under no stress conditions, the maintenance of LTP was facilitated compared with intact and sham-operated rats. The facilitation was dependent on $\beta$-adrenergic activation. These results show that reinforcement of LTP by swim stress requires an intact amygdala but no $\beta$-adrenergic activity; however, under no-stress conditions, $\beta$-adrenergic activation is required for LTP maintenance in all groups.

\section{The role of the BLA in mediating glucocorticoid effects on DG-LTP}

These results are in contrast with those of a previous study in which DG-LTP reinforcement by electrical stimulation of the BLA depended on cholinergic or $\beta$-adrenergic receptor activation (Frey et al., 2001). The failure to find such a dependency during our behavioral BLA stimulation shows that the stressactivated amygdala modulates hippocampal LTP by different pathways than the electrically stimulated amygdala. The main difference between these studies is the presence of increased levels
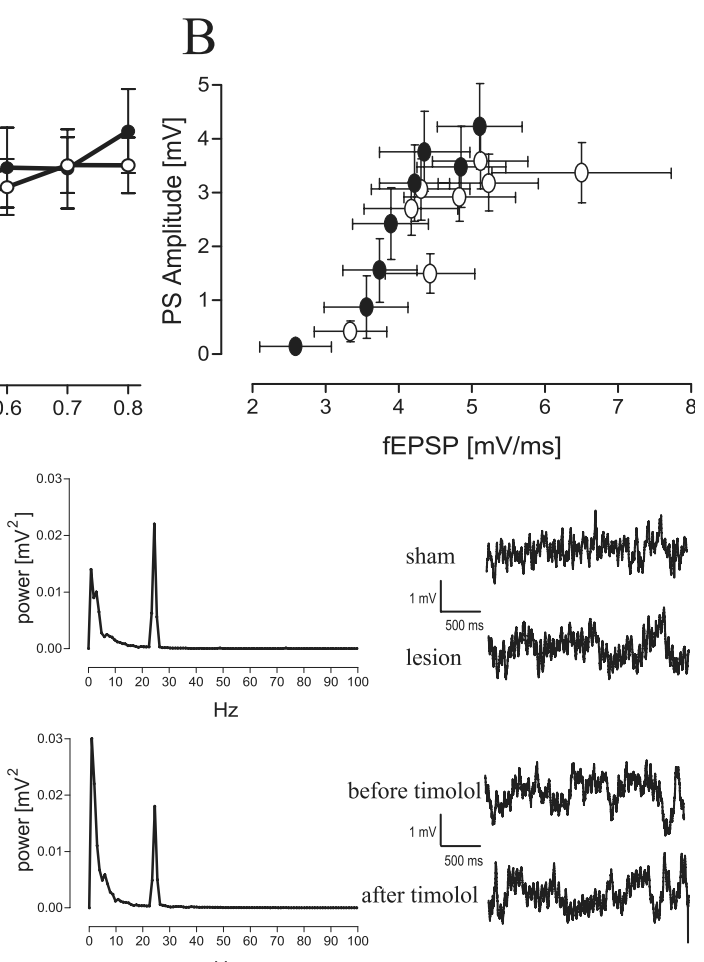

Figure 3. No difference in granule cell excitability, as indicated by the input/output curves $(\boldsymbol{A})$ and the plot of EPSP against the ilar in both groups (lesion, $n=13$; sham, $n=11$ ), as indicated by the spectral power ( $($; left, top) and after treatment with timolol ( $\boldsymbol{C}$; left, bottom) (timolol, $n=6$; saline, $n=7$ ). In the middle, power spectra for lesioned animals before (top) and 20 min after (bottom) injection of timolol are shown. The related EEG recordings are shown at the right.

of corticosterone during and after the behavioral stress condition, which may primarily contribute to the involvement of different pathways. This is supported by the finding that under no-stress conditions (i.e., under basal corticosterone titers), facilitation of LTP in lesioned animals was dependent on $\beta$-adrenergic receptor activation. In a previous study, we found that activation of MR by binding of the ligand corticosterone as well as protein synthesis were required for LTP reinforcement by swim stress (Korz and Frey, 2003). The present findings that reinforcement can be blocked by BLA lesions without manipulating MR suggest that their activation within the hippocampus may not be required or may not be sufficient for LTP reinforcement. It is very likely that an additional neuromodulatory activity, mediated by the BLA, is required, and BLA activity may be controlled by corticosterone via activation of intra-amygdalar MR receptors. Such a mechanism has been indicated in experiments by Roozendaal and McGaugh (1997) and Roozendaal (2000) for intra-amygdalar glucocorticoid receptors (GRs) in hippocampus-dependent memory consolidation. The nature of this heterosynaptic input remains to be investigated. Because of the finding that rapid nongenomic effects of MR activation on neuronal membrane properties (Chen et al., 1991; Joels and de Kloet, 1994) can modulate locomotor activity novelty dependently (Sandi et al., 1996), probably by interaction with different neurotransmitter receptors (Majewska et al., 1986; McEwen et al., 1990; Schumacher, 1990), a rapid nongenomic effect of MR may also play a role in LTP modulation.

\section{The role of the BLA in mediating $\beta$-adrenergic effects on DG-LTP}

In contrast to our results, Ikegaya et al. $(1994,1995)$ found an attenuation of DG-LTP after acute and long-lasting ipsilateral 

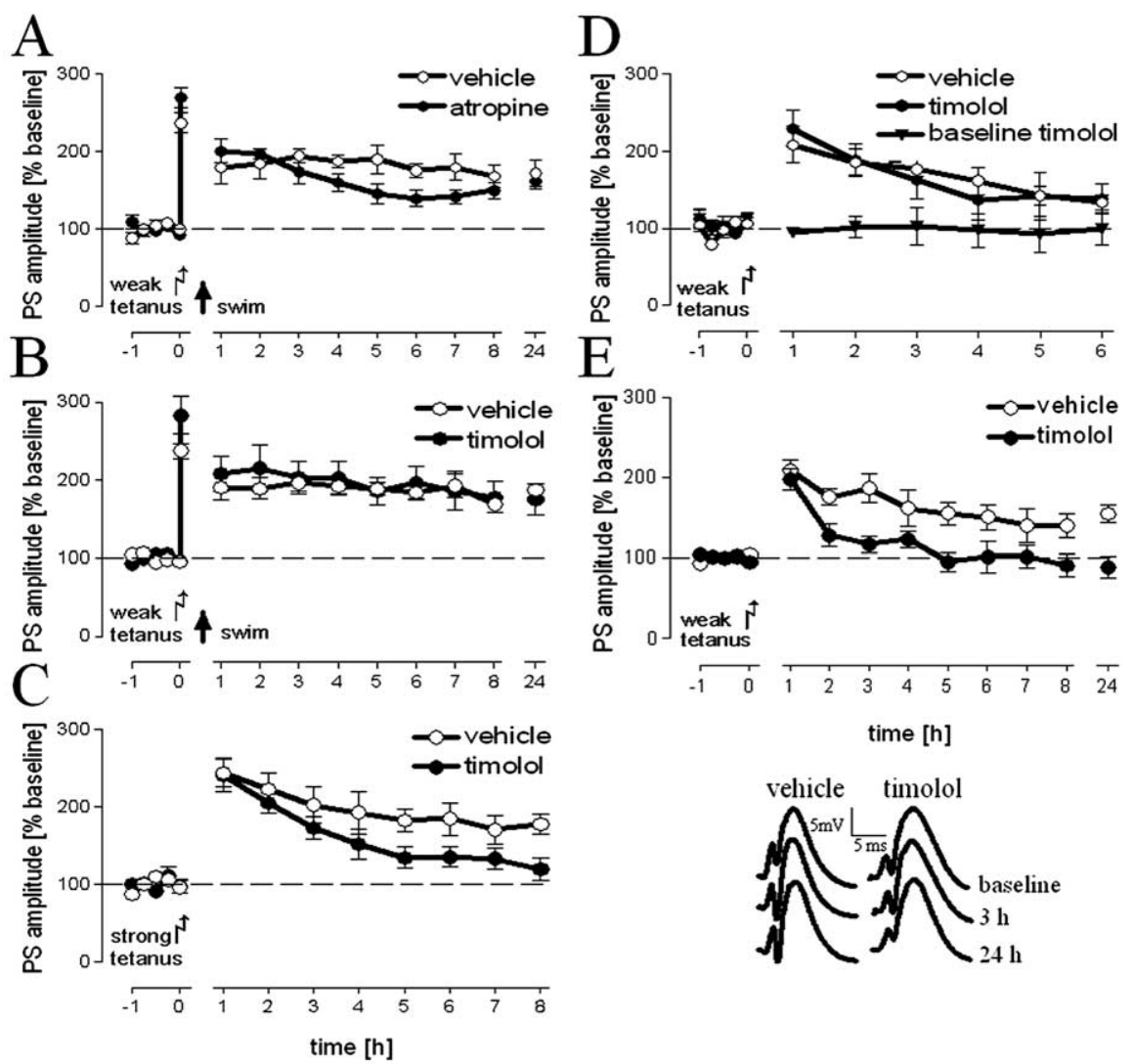

Figure 4. Applicaton of atropine $(\boldsymbol{A})$, a muscarinergic/cholinergic antagonist ( $n=8$; vehicle, $n=8)$, as well as timolol ( $n=$ 7; vehicle, $n=6)$, a $\beta$-adrenergic antagonist $(\boldsymbol{B})$, could not prevent LTP reinforcement after a 2 min swim. The same amount of timolol ( $n=8$; vehicle, $n=8$ ) was sufficient to prevent the induction of a late-LTP by a strong tetanus under no-stress condition (C). The concentration of timolol used did not affect basal transmission $(n=7)$, as well as early-LTP ( $\boldsymbol{D}$; vehicle, $n=7$; timolol, $n=5$ ), but blocked the facilitation of LTP in lesioned animals ( $\boldsymbol{E}$; vehicle, $n=8$; timolol, $n=7$ ). The mean and SEM of population-spike amplitudes as percentages from baseline values are shown. The insets are representative analog traces at the time points indicated for lesioned animals treated with vehicle or timolol.

lesion of the BLA. However, these authors used a different tetanization protocol (weak, 20 pulses at $60 \mathrm{~Hz}$; strong, 100 pulses at $100 \mathrm{~Hz}$ ) than that used in the present study, which may explain the different results. Additional work is required to characterize specific properties of LTP modulation induced by different tetanization protocols. Nakao et al. (2004) found that modulation of DG synaptic plasticity critically depends on the interplay of the stimulation strengths of the BLA and the perforant path. They propose a direct synaptic input from the BLA to the dentate gyrus via the lateral entorhinal cortex and lateral perforant path. Simultaneous strong stimulation of the BLA, together with a stimulation of the MPP, resulted in an enhanced DG-LTP, whereas a simultaneous weak stimulation of both structures resulted in enhanced long-term depression compared with weak MPP stimulation alone. During stress conditions, such a mechanism may also explain our results (i.e., that the lack of the strong input from the BLA in lesioned animals resulted in LTP impairment and, in contrast, the presence of the heterosynaptic input from the BLA reinforced DG-LTP in intact animals). However, it does not explain the LTP reinforcement in lesioned animals during no-stress conditions.

The $\beta$-adrenergic dependence of the LTP facilitation indicates either an alleviated release of norepinephrine or an increased noradrenergic tone within the hippocampus. This may be attributable to a compensatory response to the partial deafferentiation of the hippocampus by lesioning the BLA. A compensatory sprouting of central noradrenergic fibers into the DG and an upregulation of adrenergic receptors that precedes sprouting has been described by lesions of entorhinal and septal afferents to the DG (Gage et al., 1983; Morrow et al., 1983; Peterson, 1994; Jackisch et al., 1999), thus involving different neural systems in compensatory adaptations (Gold, 2004). The hypothesis of a slow compensatory mechanism would correspond with the fact that, shortly after surgery, no differences in granule cell responsiveness could be observed (AlmaguerMelian et al., 2003; our observations).

An alternative explanation is that different BLA-hippocampal pathways are involved in DG-LTP modulation under stress and no-stress conditions. Based on lesions of the fimbria-fornix, Jas et al. (2000) suggested that two independent DG-LTP modulatory pathways within the BLA-hippocampus system may exist (cf. Nakao et al., 2003), and Akirav and Richter-Levin (2002) found a $\beta$-adrenergic dependence on DG-LTP modulation by stimulating the ipsilateral but not the contralateral BLA, which also points to independent modulatory inputs.

\section{Lesioned and intact animals show similar granule cell properties and corticosterone responses}

In contrast to the study by AlmaguerMelian et al. (2003), we found no increased excitability of granule cells in lesioned and sham-operated animals compared with intact animals. However, Almaguer-Melian et al. (2003) used a stronger electrolytic lesion protocol ( $2.5 \mathrm{~mA}$ over $10 \mathrm{~s})$ than that used in the present study, and they could not rule out that, in addition to the BLA, other amygdaloid nuclei may have been affected. In addition, we found no difference in the spontaneous activity of granule cells between lesioned and intact animals. Thus, the DG-LTP facilitation observed seems to be mediated by LTP specific, rather than mere excitatory, mechanisms. In addition, the blockade of LTP reinforcement in BLA-lesioned animals cannot be explained by a different activation of the HPA-axis as indicated by similar basal and stress corticosterone levels compared with sham-operated or intact animals. Although there are some reports that BLAlesioned animals show a stronger corticosterone response to stress than controls (Seggie, 1979), most of the studies are in line with our results: lesions of the basolateral or central nuclei of the amygdala have no effect on peripheral corticosterone levels (McGregor and Herbert, 1992; Prewitt and Herman, 1997; Carter et al., 2004).

\section{Implications for emotional memory consolidation}

A dependence of basolateral amygdala $\beta$-adrenergic activity on enhanced memory retrieval (Roozendaal et al., 1999) and GR activation in the hippocampus (Roozendaal et al., 2003) has been described. Our stress paradigm was independent of GR and $\beta$-adrenergic activation but required MR activation and a yet unknown heterosynaptic input. This may suggest that different 

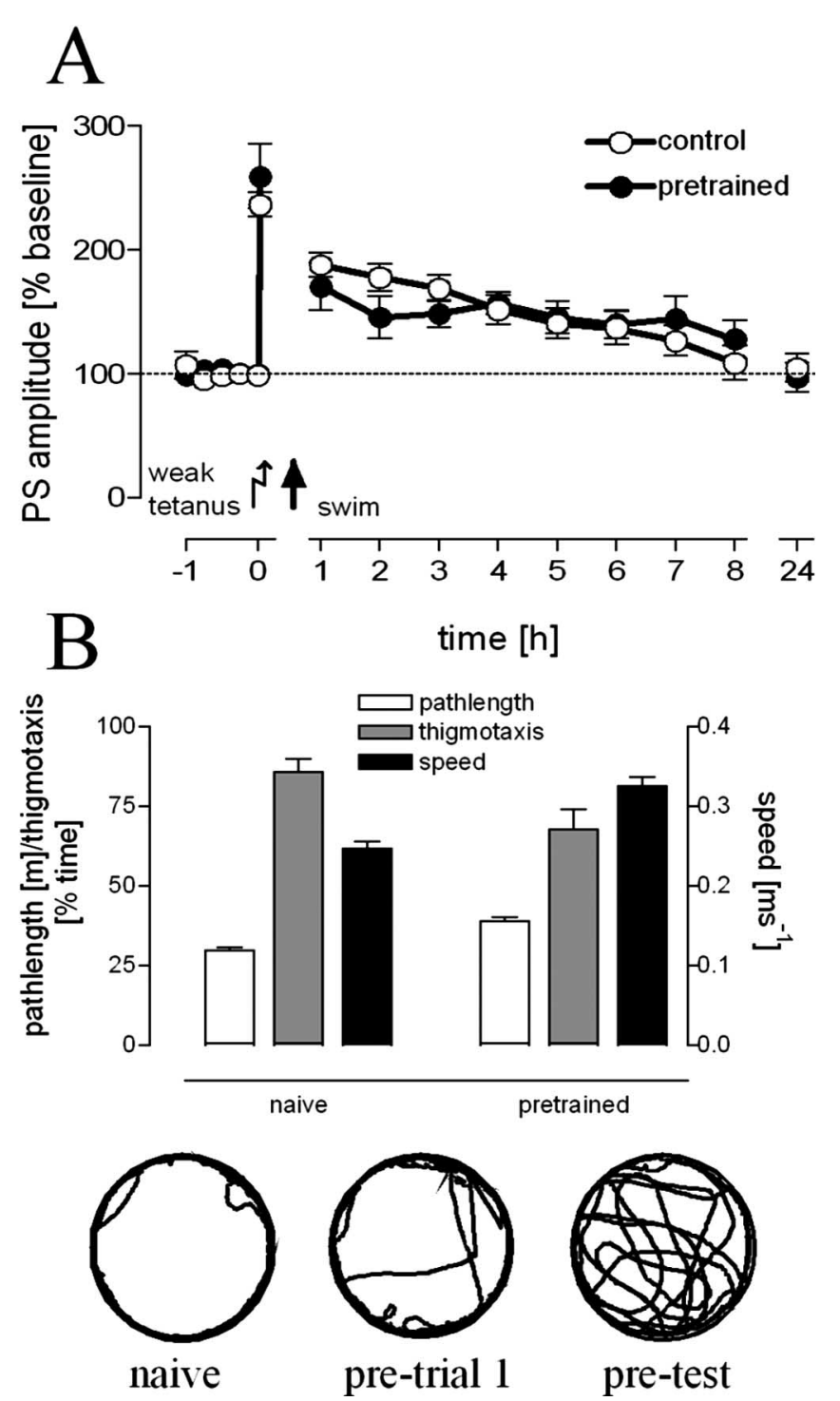

Figure 5. Pretraining prevented LTP reinforcement by swim stress $(A)$. Pretrained animals $(n=6)$ showed no prolonged maintenance of LTP compared with controls $(n=10)$. B, Pretrained animals $(n=8)$ showed increased path lengths and a higher mean swim speed but decreased amounts of thigmotaxis compared with naive animals $(n=8)$ during a 2 min swim. The insets show representative swimming paths of a naive animal and for the initial trial (pretrial 1 ) and the test trial of a pretrained animal.

neuromodulatory transmission systems are involved in DG-LTP reinforcement during stress, specific for the two corticosterone binding receptors.

The BLA seems to be the key structure in gating memory formation in other brain structures such as the hippocampus (Izquierdo and Medina, 1993; Kim et al., 1993; Vazdarjanova and McGaugh, 1999; Maren and Quirk, 2004; Rudy et al., 2004) because of its emotional significance (Roozendaal et al., 1999; Yaniv et al., 2003, 2004). Numerous projections from the amygdala to the hippocampal formation have been described previously (Pikkarainen et al., 1999; Petrovich et al., 2001) that suggest its involvement in different stages of information processing.

A single exposure to an aversive stimulation can be sufficient for corticosterone-mediated memory consolidation (Cordero et al., 2003), which is long lasting (Diamond et al., 2004; Gale et al., 2004; Izquierdo and Cammarota, 2004; Müller Igaz et al., 2004). This is in accordance with our result that briefly pretrained ani-

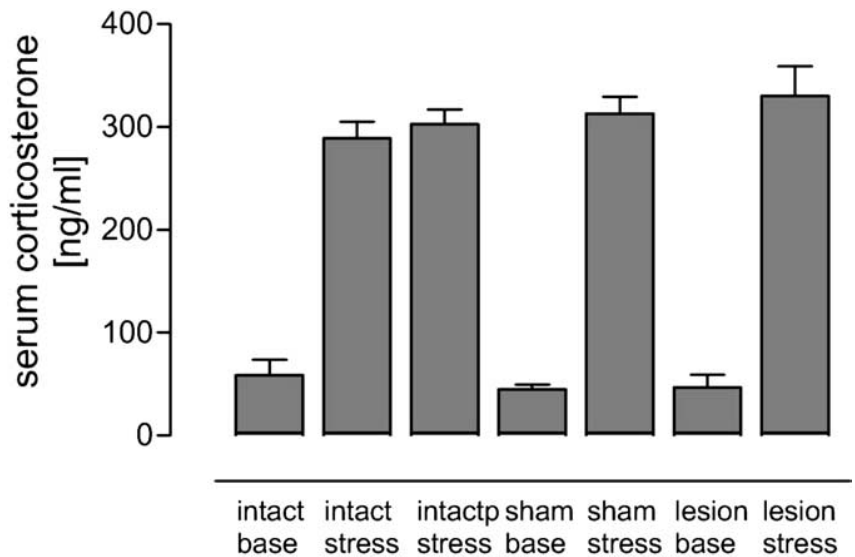

Figure 6. All stressed groups show a similar and significant increase in serum corticosterone levels $15 \mathrm{~min}$ after swimming compared with unstressed animals. This increase is independent of being naive (intact stress) or being pretrained (intactp stress). No difference between stress levels or basal levels of corticosterone could be noted between sham-operated and lesioned animals (stress: intact, $n=8$; pretrained, $n=8$; sham, $n=4$; lesioned, $n=9$; base levels: intact, $n=6$; sham, $n=3$; lesioned, $n=10$ ). Error bars represent means and SEM of serum corticosterone.

mals show no LTP reinforcement, although the corticosterone response to the test situation is similar compared with naive animals. A consolidation of contextual memory is indicated by the decrease of thigmotaxis (usually seen as fear-related behavior) and the higher swim speed in pretrained compared with naive rats during the test situation.

Our data suggest that DG-LTP maintenance can be influenced by the BLA through different mechanisms: a short-lasting corticosterone-dependent and $\beta$-adrenergic-independent mechanism and a long-lasting mechanism that facilitated hippocampal $\beta$-adrenergic mechanisms. Because of its appearance during basal corticosterone levels, the latter may be independent on corticosterone, compensating for reduced or missing BLA inputs probably involving different brain structures.

\section{References}

Abe K, Nakata A, Mizutani A, Saito H (1994) Facilitatory but nonessential role of the muscarinic cholinergic system in the generation of long-term potentiation of population spikes in the dentate gyrus in vivo. Neuropharmacology 33:847-852.

Akirav I, Richter-Levin G (1999) Biphasic modulation of hippocampal plasticity by behavioral stress and basolateral amygdala stimulation in the rat. J Neurosci 19:10530-10535.

Akirav I, Richter-Levin G (2002) Mechanisms of amygdala modulation of hippocampal plasticity. J Neurosci 22:9912-9921.

Almaguer-Melian W, Martinez-Marti L, Frey JU, Bergado JA (2003) The amygdala is part of the behavioural reinforcement system modulating long-term potentiation in rat hippocampus. Neuroscience 119:319-322.

Bergado JA, Almaguer-Melian W, Kostenko S, Frey S, Frey JU (2003) Behavioral reinforcement of long-term potentiation in rat dentate gyrus in vivo is protein synthesis-dependent. Neurosci Lett 351:56-58.

Carter RN, Pinnock SB, Herbert J (2004) Does the amygdala modulate adaptation to repeated stress? Neuroscience 126:9-19.

Chen YZ, Hua SY, Wang CA, Wu LG, Gu Q, Xing BR (1991) An electrophysiological study on the membrane receptor-mediated action of glucocorticoids in mammalian neurons. Neuroendocrinology 53:25-30.

Cordero MI, Venero C, Kruyt ND, Sandi C (2003) Prior exposure to a single stress session facilitates subsequent contextual fear conditioning in rats. Evidence for a role of corticosterone. Horm Behav 44:338-345.

Diamond DM, Park CR, Woodson JC (2004) Stress generates emotional memories and retrograde amnesia by inducing an endogenous form of hippocampal LTP. Hippocampus 14:675-676.

Frey S, Bergado-Rosado J, Seidenbecher T, Pape HC, Frey JU (2001) Reinforcement of early long-term potentiation (early-LTP) in dentate gyrus by 
stimulation of the basolateral amygdala: heterosynaptic induction mechanisms of late-LTP. J Neurosci 21:3697-3703.

Frey S, Bergado JA, Frey JU (2003) Modulation of late phases of long-term potentiation in rat dentate gyrus by stimulation of the medial septum. Neuroscience 118:1055-1062.

Frey U, Krug M, Reymann KG, Matthies H (1988) Anisomycin, an inhibitor of protein synthesis, blocks late phases of LTP phenomena in the hippocampal CA1 region in vitro. Brain Res 452:57-65.

Frey U, Schroeder H, Matthies H (1990) Dopaminergic antagonists prevent long-term maintenance of posttetanic LTP in the CA1 region of rat hippocampal slices. Brain Res 522:69-75.

Frey U, Matthies H, Reymann KG, Matthies H (1991) The effect of dopaminergic D1 receptor blockade during tetanization on the expression of long-term potentiation in the rat CAl region in vitro. Neurosci Lett 129:111-1114.

Frey U, Huang YY, Kandel ER (1993) Effects of cAMP simulate a late stage of LTP in hippocampal CA1 neurons. Science 260:1661-1664.

Gage FH, Bjorklund A, Stenevi U, Dunnett SB (1983) Functional correlates of compensatory collateral sprouting by aminergic and cholinergic afferents in the hippocampal formation. Brain Res 268:39-47.

Gale GD, Anagnostaras SG, Godsil BP, Mitchell S, Nozawa T, Sage JR, Wiltgen B, Fanselow MS (2004) Role of the basolateral amygdala in the storage of fear memories across the adult lifetime of rats. J Neurosci 24:3810-3815.

Gold PE (2004) Coordination of multiple memory systems. Neurobiol Learn Mem 82:230-242.

Hentall ID, Kurle PJ, White TR (2000) Correlations between serotonin level and single-cell firing in the rat's nucleus raphe magnus. Neuroscience 95:1081-1088.

Ikegaya Y, Saito H, Abe K (1994) Attenuated hippocampal long-term potentiation in basolateral amygdala-lesioned rats. Brain Res 656:157-164.

Ikegaya Y, Saito H, Abe K (1995) Requirement of basolateral amygdala neuron activity for the induction of long-term potentiation in the dentate gyrus in vivo. Brain Res 671:351-354.

Ikegaya Y, Saito H, Abe K (1996) Dentate gyrus field potentials evoked by stimulation of the basolateral amygdaloid nucleus in anesthetized rats. Brain Res 718:53-60.

Ikegaya Y, Nakanishi K, Saito H, Abe K (1997) Amygdala betanoradrenergic influence on hippocampal long-term potentiation in vivo. NeuroReport 8:3143-3146.

Izquierdo I (1994) Pharmacological evidence for a role of long-term potentiation in memory. FASEB J 8:1139-1145.

Izquierdo I, Cammarota M (2004) Zif and the survival of memory. Science 304:829-830.

Izquierdo I, Medina JH (1993) Role of the amygdala, hippocampus and entorhinal cortex in memory consolidation and expression. Braz J Med Biol Res 26:573-589.

Jackisch R, Stemmelin J, Neufang B, Lauth D, Neughebauer B, Kelche C, Cassel JC (1999) Sympathetic sprouting: no evidence for muscarinergic modulation of noradrenaline release in hippocampal slices of rats with fimbria-fornix lesions. Exp Brain Res 124:17-24.

Jas J, Almaguer W, Frey JU, Bergado J (2000) Lesioning the fimbria-fornix impairs basolateral amygdala induced reinforcement of LTP in the dentate gyrus. Brain Res 861:186-189.

Joels M, de Kloet ER (1994) Mineralocorticoid and glucocorticoids receptors in the brain. Implications for ion permeability and transmitter systems. Prog Neurobiol 43:1-36.

Kasamo K, Tada K, Ueda N, Kojima T, Kogure M, Ishikawa K (1994) Effects of several 5-HT1A agonists on hippocampal rhythmical slow activity in unanesthetized rats. Neuropharmacology 33:905-914.

Kim JJ, Diamond DM (2002) The stressed hippocampus, synaptic plasticity and lost memories. Nat Rev Neurosci 3:453-462.

Kim JJ, Rison RA, Fanselow MS (1993) Effects of amygdala, hippocampus, and periaqueductal gray lesions on short- and long-term contextual fear. Behav Neurosci 107:1093-1098.

Korz V, Frey JU (2003) Stress-related modulation of hippocampal longterm potentiation in rats: involvement of adrenal steroid receptors. J Neurosci 23:7281-7287.

Korz V, Frey JU (2004) Emotional and cognitive reinforcement of rat hippocampal long-term potentiation by different learning paradigms. Neuron Glia Biol 1:253-261.
Krug M, Lossner B, Ott T (1984) Anisomycin blocks the late phase of longterm potentiation in the dentate gyrus of freely moving rats. Brain Res Bull 13:39-42.

Majewska MD, Harrison NL, Schwartz RD, Barker JL, Paul SM (1986) Steroid hormone metabolites are barbiturate-like modulators of the GABA receptor. Science 232:1004-1007.

Maren S, Quirk GJ (2004) Neuronal signalling of fear memory. Nat Rev Neurosci 5:844-852.

McEwen BS, Coirini H, Schumacher M (1990) Steroid effects on neuronal activity: when is the genome involved? Ciba Found Symp 153:3-12.

McGaugh JL (2002) Memory consolidation and the amygdala: a systems perspective. Trends Neurosci 25:456-461.

McGaugh JL (2004) The amygdala modulates the consolidation of memories of emotionally arousing experiences. Annu Rev Neurosci 27:1-28.

McGregor A, Herbert J (1992) Differential effects of excitotoxic basolateral and corticomedial lesions of the amygdala on the behavioural and endocrine responses to either sexual or aggression-promoting stimuli in the male rat. Brain Res 574:9-20.

Morrow AL, Loy R, Creese I (1983) Septal deafferentiation increases hippocampal adrenergic receptors: correlation with sympathetic axon sprouting. Proc Natl Acad Sci USA 80:6718-6722.

Müller Igaz L, Bekinschtein P, Izquierdo I, Medina JH (2004) One-trial aversive learning induces late changes in hippocampal CaMKII $\alpha$, Homer 1a, Syntaxin 1a and ERK2 protein levels. Mol Brain Res 132:1-12.

Nakao K, Ikegaya Y, Yamada MK, Nishiyama N, Matsuki N (2003) Fimbrial control of bidirectional synaptic plasticity of medial perforant pathdentate transmission. Synapse 47:163-168.

Nakao K, Matsuyama K, Matsuki N, Ikegaya Y (2004) Amygdala stimulation modulates hippocampal synaptic plasticity. Proc Natl Acad Sci USA 101:14270-14275.

Otani S, Ben-Ari Y (1993) Biochemical correlates of long-term potentiation in hippocampal synapses. Int Rev Neurobiol 35:1-41.

Otani S, Marshall CJ, Tate WP, Goddard GV, Abraham WC (1989) Maintenance of long-term potentiation in rat dentate gyrus requires protein synthesis but not messenger RNA synthesis immediately posttetanization. Neuroscience 28:519-526.

Peterson GM (1994) Sprouting of central noradrenergic fibers in the dentate gyrus following combined lesion of its entorhinal and septal afferents. Hippocampus 4:635-648.

Petrovich GD, Canteras NS, Swanson LW (2001) Combinatorial amygdalar inputs to hippocampal domains and hypothalamic behaviour systems. Brain Res Brain Res Rev 38:247-289.

Pikkarainen M, Rönkkö S, Savander V, Insausti R, Pitkänen A (1999) Projections from the lateral, basal, and accessory basal nuclei of the amygdala to the hippocampal formation in rat. J Comp Neurol 403:229-260.

Prewitt CM, Herman JP (1997) Hypothalamo-pituitary-adrenocortical regulation following lesions of the central nucleus of the amygdala. Stress 1:263-280.

Roozendaal B (2000) Glucocorticoids and the regulation of memory consolidation. Psychoneuroendocrinology 25:213-238.

Roozendaal B (2003) Systems mediating acute glucocorticoid effects on memory consolidation and retrieval. Prog Neuropsychopharmacol Biol Psychiatry 27:1213-1223.

Roozendaal B, McGaugh JL (1997) Glucocorticoid receptor agonist and antagonist administration into the basolateral but not central amygdala modulates memory storage. Neurobiol Learn Mem 67:176-179.

Roozendaal B, Nguyen BT, Power AE, McGaugh JL (1999) Basolateral amygdala noradrenergic influence enables enhancement of memory consolidation induced by hippocampal glucocorticoid receptor activation. Proc Natl Acad Sci USA 96:11642-11647.

Roozendaal B, Griffith QK, Buranday J, deq Uervain DJF, McGaugh JL (2003) The hippocampus mediates glucocorticoid-induced impairment of spatial memory retrieval: dependence on the basolateral amygdala. Proc Natl Acad Sci USA 100:1328-1333.

Roozendaal B, Hahn EL, Nathan SV, deq Uervain DJF, McGaugh JL (2004) Glucocorticoid effects on memory retrieval require concurrent noradrenergic activity in the hippocampus and the basolateral amygdala. J Neurosci 24:8161-8169.

Rudy JW, Huff NC, Matus-Amat P (2004) Understanding contextual fear conditioning: insights from a two-process model. Neurosci Biobehav Rev 28:675-685. 
Sajikumar S, Frey JU (2004) Late-associativity, synaptic tagging, and the role of dopamine during LTP and LTD. Neurobiol Learn Mem 82:12-25.

Sandi C, Venero C, Guaza C (1996) Novelty-related rapid locomotor effects of corticosterone in rats. Eur J Neurosci 8:794-800.

Schumacher M (1990) Rapid membrane effects of steroid hormones: an emerging concept in neuroendocrinology. Trends Neurosci 13:359-362.

Seggie J (1979) Differential effects of basolateral amygdala lesions on behavior, corticosterone, and prolactin response. Psychiatry Res 1:283-295.

Seidenbecher T, Reymann KG, Balschun D (1997) A post-tetanic time window for the reinforcement of long-term potentiation by appetitive and aversive stimuli. Proc Natl Acad Sci USA 94:1494-1499.

Seidenbecher T, Laxmi TR, Stork O, Pape HC (2003) Amygdalar and hippocampal theta rhythm synchronization during fear memory retrieval. Science 301:846-850.

Straube T, Korz V, Balschun D, Frey JU (2003) Novelty-exploration induces a protein synthesis-dependent late phase of long-term potentiation: involvement of $\beta$-adrenergic receptors. J Physiol (Lond) 552:953-960.
Uzakov S, Frey JU, Korz V (2005) Reinforcement of rat hippocampal LTP by holeboard training. Learn Mem 12:165-171.

Vazdarjanova A, McGaugh JL (1999) Basolateral amygdala is involved in modulating consolidation of memory for classical fear conditioning. J Neurosci 19:6615-6622.

Vouimba RM, Richter-Levin G (2005) Physiological dissociation in hippocampal subregions in response to amygdala stimulation. Cereb Cortex, in press.

Yaniv D, Vouimba RM, Diamond DM, Richter-Levin G (2003) Simultaneous induction of long-term potentiation in the hippocampus and the amygdala by entorhinal cortex activation: mechanistic and temporal profiles. Neuroscience 120:1125-1135.

Yaniv D, Desmedt A, Jaffard R, Richter-Levin G (2004) The amygdala and appraisal processes: stimulus and response complexity as an organizing factor. Brain Res Brain Res Rev 44:179-186.

Zhelyazkova-Savova MD, Zhelyazkov DK (2003) Behavioural evidence of agonist-like effect of isoteoline at 5-HT1B serotonergic receptors in mice. J Pharm Pharmacol 55:125-129. 